\title{
REAL-TIME AIR POLLUTION MONITORING AND CONTROLLING
}

\author{
Prachit Kurani ${ }^{1}$, Yash Shah ${ }^{2}$ \\ ${ }^{1}$ B.E at K J Somaiya College of Engineering, Mumbai, INDIA \\ prachit.kurani@gmail.com; prachit.k@somaiya.edu \\ ${ }^{2}$ Student of K.J. Somaiya College Of Engineering, Mumbai, INDIA \\ yash_664@yahoo.co.in, yashshah664@gmail.com
}

\begin{abstract}
This paper presents Real-Time system for air pollution monitoring and control. The main objective of the work is designing microcontroller based toxic gas detecting and alerting system. This is a semi-automated system such that if the pollution level exceeds the normal level then an alarm is generated immediately and also an alert message (SMS) is sent to the authorized person through the GSM. Along with this the ionizer responsible for reducing the level of pollutants too would be started by the system. Time to time detected data would be stored into database for further retrieval.
\end{abstract}

\section{Indexing terms/Keywords}

Air Pollution, Atmosphere, Environmental Technology, Clean Air, degree of pollutants, Ionizer Kit, level of gases, Air Pollution monitoring, Gas Sensor.

\section{Academic Discipline And Sub-Disciplines}

Engineering, Microcontrollers, Environment, Technology

\section{SUBJECT CLASSIFICATION}

Hardware components interfaced with software using java.

\section{TYPE (METHOD/APPROACH)}

The research got initiated by the looking at the current scenario of pollution and some technologies iniitatiated by various authors and publishers, software logicapproached with the help of authorRajKamal.

\section{Council for Innovative Research}

Peer Review Research Publishing System

Journal: International Journal of Management \& Information Technology

Vol. 8, No. 3

editor@cirworld.com

www.cirworld.com, member.cirworld.com 


\section{INTRODUCTION}

Air pollution is one of the most serious problems in the world. It refers to the contamination of the Atmosphere by harmful chemicals or biological matter. Air pollution in today's generation is a serious upcoming issue causing harm to humans as well as environment in different ways. Along with increasing influence of technology, the level of pollution too is rising. The literature is extensively reviewed in order to evaluate this project on embedded system for the pollution control. In particular, the focus is on the description of the ionizer kit, which is controlled by microcontroller in order to reduce the pollutants in air and makes use of sensors for detection of pollutants.

This is an embedded system project which will be developed as:

A System of sensors that checks the level of air pollution, displays degree of pollutants to user and reduces the pollutants to produce optimized level of fresh air for the residents. To control and reduce the pollutants in air, the system uses a kit called ionizer and makes air healthier to respire. The sensors monitor amount of pollutants in air and on crossing particular threshold it will alert the users by the alarm system at the same time to dump the pollutants microcontroller will activate the ionizer kit which emits stream of negative ions to reduce the pollutants.

\section{Aims and Objectives:}

1. By using sensors and displaying data to user, buzzer system and GSM, it monitors level of gases in the air as well as alerts the resident.

2. The system uses a kit called 'Ionizer Kit' to control and reduce the pollutants in air and makes air healthier to respire.

\section{METHOD}

"Air Pollution Monitoring and Controlling System" which will be divided in two parts:

1. Hardware

\section{Software}

The Hardware circuit comprises of detection and compression system where as software will interface the circuit with the Machine using Java.

\section{The working of system will be as follows:}

The start command given through the software interface will activate the air pollution sensor and detection of pollutants will be started. The total pollution percentage will be received from the com port via RS232 interface. The retrieved information will be stored in the database. Only authorized users can view the information of previous scans by retrieving it from the database. After detecting and storing the percentage value, the next step is to dump the pollutants which will be done with the help of IONIZER circuit.

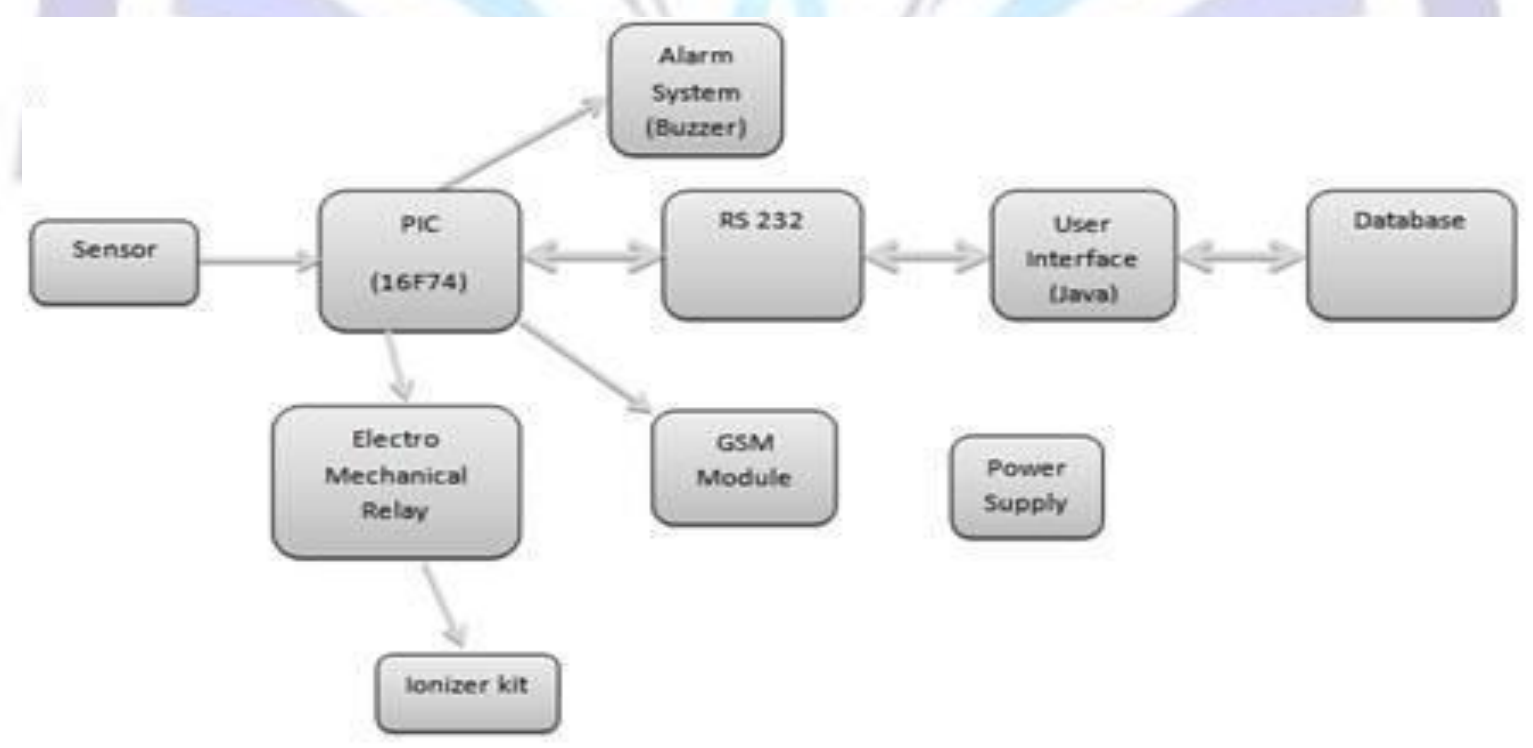

Fig 1: Block Diagram 
The implementation of proposed system compared to the existing one is that it includes PIC microcontroller for compactness, GSM module to message the authorized user, buzzer to alert the user and the ionizer to curb the pollutants. Rooms are made healthier for those suffering from asthma, allergies, impaired immunity, or respiratory ailments. We can install this device wherever there is huge amount of pollution as it tries to keep the level of air pollution in check and at the same time "Purify" it. So it also plays a major role in purifying the air and thus trying to make the surrounding air "POLLUTION FREE".

\section{Environment Monitoring requirement are:}

1- A better measurement of the pollutant concentrations and their variations.

2- Rapid alert of the critical situation.

3- Continuous functioning.

4- Autonomous power supply.

5- Severe environment functioning.

\section{MATERIALS}

\section{A- Ionizer:}

The ionizer is a kit which is responsible for compression of pollutants. It performs its work by emitting streams of negative ions into the air. If they collide with particles of smoke or pollution, they pass on their "static" charge. This particle is then strongly attracted to the nearest "earthed" surface (which could be a wall or the shelf on which the ionizer is placed).

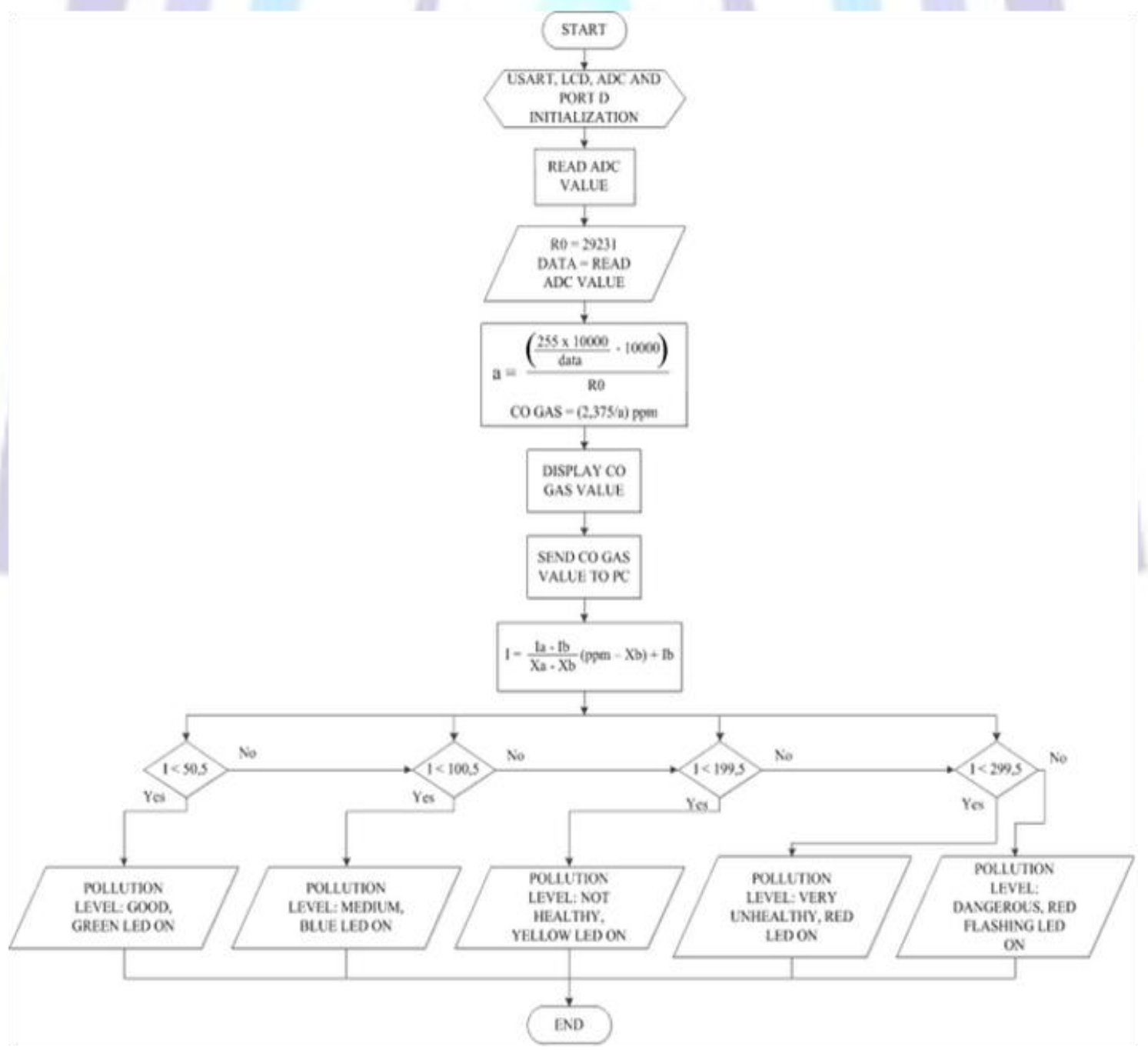

Fig 2: Flow Chart 
As they drift, pollutants such as dust, pollen, cigarette smoke and even vaporized substances like aerosol propellants and car fumes are attracted and clustered around the ions. This has the effect of making the ion grow in size. When the ions become too heavy to be carried in the air, it falls to the ground. The ability of an ionizer to remove very fine particles from the air makes it extremely valuable for health. It is effective for all types of pollutants right from particulate pollutants like dust particles to gaseous pollutants like aerosols.

\section{B. Gas Sensor-MQ7:}

The main to detect the amount of pollution in the atmosphere is done with the help of gas sensor. It is mainly used to detect the $\mathrm{CO}$ gases in the air.

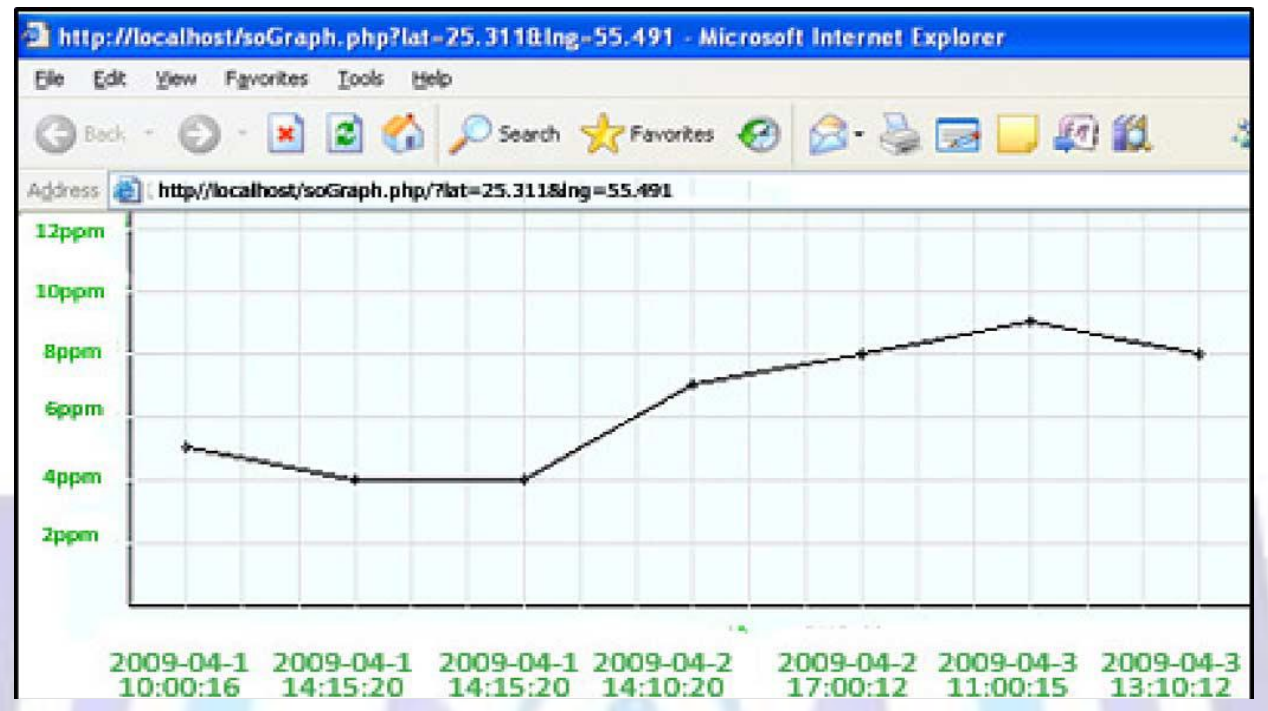

Fig 3: History of $\mathrm{CO}$ pollutant levels.

Its various features are as:

1- Fast response.

2- Stable and long life.

3- Simple drive circuit.

4- High sensitivity to $\mathrm{CH} 4$ and Natural gas.

5- Small sensitivity to alcohol and smoke.

\section{Microcontroller - PIC (16f7X):}

1- PIC $16 c 6 x / 16 c 7 x$ is used for learning purpose.

2- Different bus widths of data and program memory; Data memory is 8 bit wide where as program memory is $12,14,16$ bits wide. The instruction holds immediate data along with instruction code.

3- It consists of 35 instructions.

4- Most instructions take 0.2 microsecond to execute when operated at $20 \mathrm{MHz}$. Machine cycle consist of 4 clock pulses.

5- Instruction set is highly orthogonal.

6- 3-12 interrupt Sources, 4/8 Channel, 8 bit on chip ADC, Power on Reset (POR), Brown out Reset (BOR), Capture/Compare/ PWM modules, USART, Synchronous serial port (SSP) with SPI and I2C, Power saving SLEEP mode.

7- Wide operating Voltage ranges from $2.5 \mathrm{~V}$ to 6.0 i.e. Very Low power consumption.

8- Commercial, Industrial and Extended Temperature ranges.

9- Parallel slave port (PSP), 8 bits wide with external RD, WR and CS controls.

\section{User Interface:}


We have a computer to interact with the user and to display level of pollutants in air, also at the same time after the ionizer kit has reduced the pollutants; we have the computer to display optimized level of gases in the air.

The computer also maintains a database about level of pollutants in the air throughout the day, weeks and months.

\section{TGS 2600 Gas Sensor:}

The TGS 2600 has high sensitivity to low concentrations of gaseous air contaminants such as hydrogen and carbon monoxide which exist in cigarette smoke. The sensor can detect hydrogen at a level of several ppm. Figaro also offers a microprocessor (FIC02667) which contains special software for handling the sensor signals for appliance control applications.

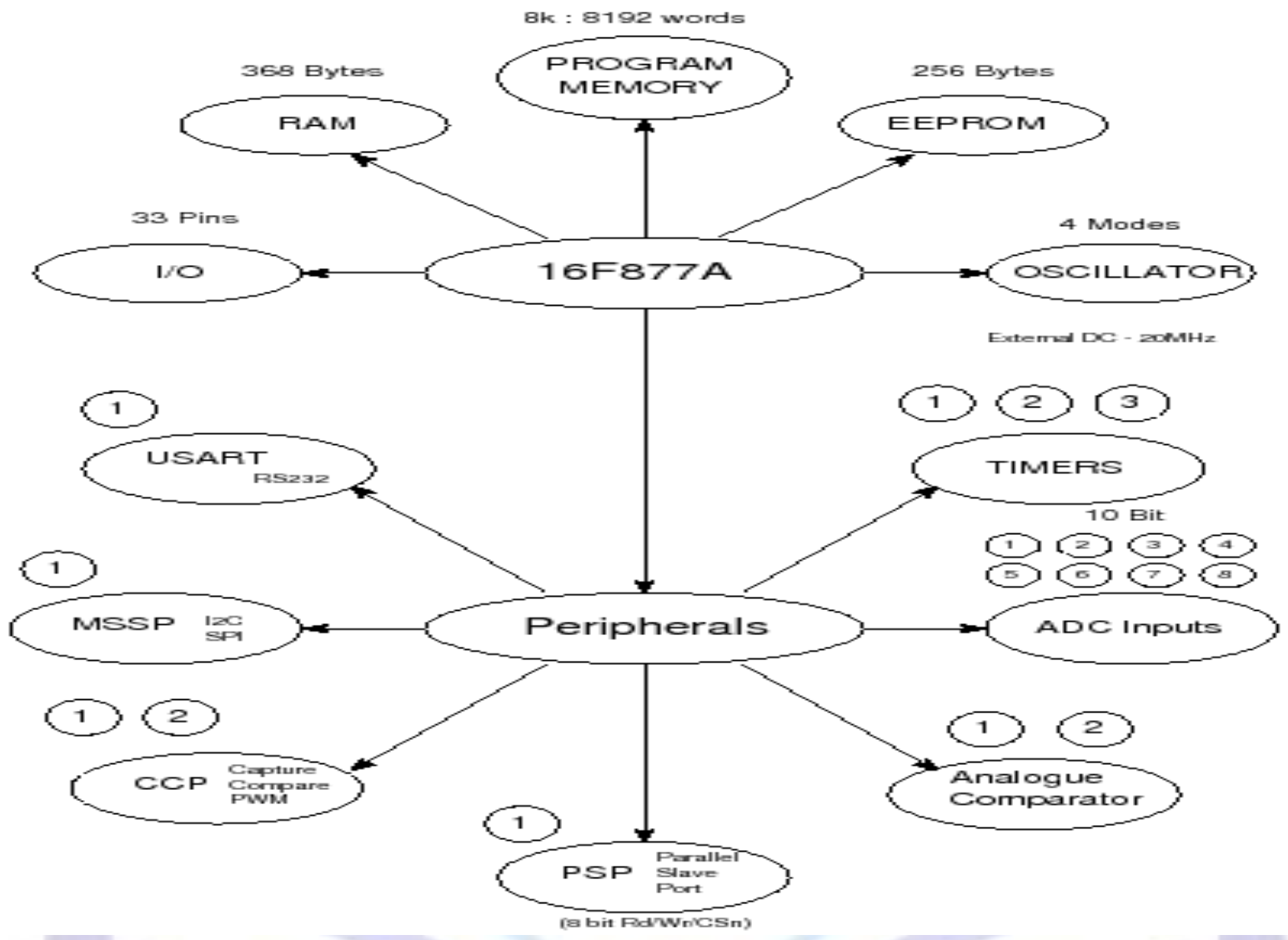

Fig 4: PIC functional diagram

Features:

1. Low power consumption

2. High sensitivity to gaseous air contaminants

3. Long life and low cost

4. Uses simple electrical circuit

5. Small size

\section{Application:}

1. Air cleaners

2. Ventilation control

3. Air quality monitors 


\section{CONCLUSION}

The air purifier eliminates odours from moulds, pollens, allergies, chemical gases, dust, tobacco smoke, pet smells, paint fumes, foods and beverages, which causes sneezing, asthma, itchy eyes, sinus and ear irritations.

\section{WHERE TO USE}

Homes \& Living Areas; Offices \& Stores; New Paint \& Wallpaper Areas; Hospitals \& Nursing Homes; Veterinary Offices; Smoking Areas; Hotel Rooms; High Pollen Environments; Laundry Rooms; Medical Offices; Day Care Centres; Stables \& Aviaries; Locker Rooms; Restaurants \& Bars

The most important conclusion is that this system is effective for all types of pollutants right from particulate pollutant like dust particles to gaseous pollutants like Aerosols. This system also requires less maintenance. It is quieter than other filter-based air purifiers. It is a small step in making the life of future generation more "enhanced and healthier" otherwise air pollution "SLOWLY BUT SURELY WILL BRING GREAT HUMAN CIVILIZATION TO ITS BITTER END".

\section{ACKNOWLEDGMENTS}

We would like to thank our family for motivating us in all the possible aspects and nurturing us to create the ability to think about the research work. Our token of appreciation would be to the experts who made it simpler for us to complete our research activity. Lastly, we would also like to thank IJMIT for giving us the opportunity and platform to present our paper globally.

\section{REFERENCES}

[1] Tajne K.M, Rathore S.S, Asutkar G.M -"Monitoring of Air Pollution using Wireless Sensors - A case study of monitoring air pollution in Nagpur city"

[2] V.Ramya, B. Palaniappan-“Embedded System for Hazardous Gas Detection and Alerting"

[3] Raj Kamal, "Embedded System Architecture Programming and Design" TATA Mc-Graw Hill.

[4] http://airccse.org/journal/ijdps/papers/0512ijdps24.pdf

[5] http://ijcae.org/admin/journals/Journals768.pdf

[6] http://www.bvmengineering.ac.in/docs/published\%20papers/etel/etel/401004.pdf

[7] http://www.bigclive.com/ioniser.html

[8] http://ieeexplore.ieee.org/xpl/login.jsp?tp=\&arnumber=4459727\&url=http\%3A\%2F\%2Fieeexplore.i eee.org\%2Fiel\%2F7361\%2F4453907\%2F04459727.pdf\%3Farnumber\%3D445972

\section{Author Biography}

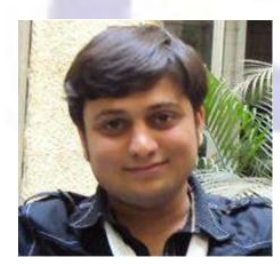

\section{Prachit Kurani}

Bachelor of Engineering at $\mathrm{K} \mathrm{J}$ Somaiya College of Engineering (Mumbai UniversityIndia), specialized in Electronics in May 2013.Currently working at Neebal Learning Pvt Ltd. as Research Analyst Trainee and Teaching Assistant.

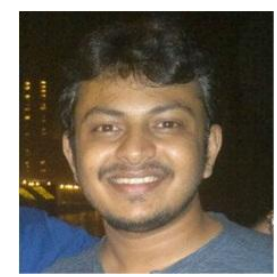

\section{Yash Shah}

Pursuing Bachelor of Engineering from $\mathrm{K} \mathrm{J}$ Somaiya College of Enginenering (Mumbai University-India), specializing in Electronics.Worked as an intern at P2S Information Systems, pricepaaji.com and Net Vigil Software Pvt Ltd. 